\title{
A Review of the Effects of Mother-Father Relationship on Academic Performance of Students
}

\author{
Aming'a Robert Maina* and Kisilu Kitainge \\ Science Education Department, School of Education, University of Eldoret, Kenya
}

\begin{abstract}
For child proper emotional maturity, mother and father's love and affection are essential requirements for child's emotional stability; children have certain emotional needs that have to be catered for if they have to gain emotional stability. It can be noted that children brought up in a home devoid of love and care most times grow up with unwanted characters in the society. This paper reviews the research literature on the effects of family relationship on student academic performance with special reference to MFR (Mother-Father Relationship). The study is a developmental study that takes into account the social trends and economic conditions in predictions to the future status of a family as a block. The results first present how MFR variable correlate with academic performance of students before tackling the general constructs described in the literature. At the end of this review, the finding results have been discussed in light of the different effects of mother-father relationship on child academic performance.
\end{abstract}

Keywords: Mother; Father; Relationship

\section{Introduction}

There is no simple definition of a family; basically, it's a group of individuals who share a legal or genetic bond. According to Oxford Dictionary a family is a group consisting of one or two parents and their children. Despite the simplicity of this definition, to many people especially in Africa a family definition goes far beyond legal or blood relationships. Biologically a family is an institution formed to produce and raise one's children while ensuring biological continuity. In other words, biological parents may have other hidden motivations to the universal growth of their children compared to other parents. Marsiglio suggests that biological fathers are naturally self motivated to invest time, energy, money and other resources for the well-being of their children in contrast to step fathers to who he states must be motivated by other external factors to support children. In other words experiences in early childhood development shape a person's behaviour and may affect his/her lifelong experiences. Children thrive in a nurturing environment where there is promising expectations.

\section{Background of the Study}

Mother-father relationships in a family comes with both positive outcomes such as happiness, understanding and positive child growth, and negative outcomes such as family stress, divorce or repeated conflicts. These relationship effects have deep and lasting impacts on the physical, emotional and cognitive development of a child, and thus put them into social and economic dangers. It is absolute that biological parents tend to confer multiple developmental assets for their children, this may include, care giving stability, economic resources and quality parenting and supervision, which transforms into a positive academic and behaviourial outcomes. In contrast children in cohabiting-parent or single parent families show poor academic achievement and behavioural outcomes than children in married and more so biologically. Likewise children in a family that is composed of a remarriage structure following divorce or death of one partner are academically and behaviourally similar with those in cohabiting-parent homes.

According to psychologist Dalton Perterson, "A family unit is like a sponge, they model each other and incorporate what they see and experience from each other into their lives". There is also evidence to suggest that family environment, pattern and parenting styles affects the developmental process of children, that is, emotionally, behavioural and socially [1]. Infighting and arguing among parents that is destructive such that it involves verbal and physical fights makes children feel they are to be blamed for the parents disagreements and may in turn traumatize them in the long run. Rather if this disagreements are covered up with maturity, a child is likely to benefit from how conflicts are resolved, and may replicate such a behavior in future to others since he will feel its normal [2].

Several researches point out that family stability is an important factor in child development as well as family as a whole. Tony states that the relationship between both parents is an essential ingredient of family functioning and a major influence on the well-being of a child, this can therefore be attributed to the child's behavioural development and school performance. Any changes in the composition of a family may in one way or another influence the child as by the quality and character of families in which children are exposed to at any given time. In their research Paula and Cynthia established that any disruptions to the family system be it by addition or departure of a parent's partner or spouse leads to deleterious long term behaviours among the children. Family structure transitions often exposes children to conflicts prior to dissolution in-turn undermining children's successful development in almost all spheres of life, considering, that the exposure to these conflicts affects children's socio-emotional development, academic performance and the transition from childhood to maturity, and further compounding negative effects on children's development.

A research study conducted by Adams on the effects of parent on child development indicated that children raised up in a family of

*Corresponding author: Aminga Robert Maina, Science Education Department, School of Education, University of Eldoret, Kenya, Tel: +254 727543807; E-mail: aminga2006@yahoo.com

Received February 09, 2018; Accepted February 15, 2018; Published February 22, 2018

Citation: Maina AR, Kitainge K (2018) A Review of the Effects of Mother-Father Relationship on Academic Performance of Students. Arts Social Sci J 9: 339. doi: 10.4172/2151-6200.1000339

Copyright: ( 2018 Maina AR, et al. This is an open-access article distributed under the terms of the Creative Commons Attribution License, which permits unrestricted use, distribution, and reproduction in any medium, provided the original author and source are credited. 
single parent or in a non-biological family usually lack social support and frequently experience residential mobility and health problems [1]. These factors in the end transforms into cognitive difficulties and behavioural problems [1]. It is therefore paramount that parent relational well-being be keenly observed considering its importance in terms of a family's economic success, success of children in schools and their future lives. Several studies reveal that one's childhood parenting has significant and lasting effects on his/her health and well-being. According to Lehman, et al. poor parent relationship is a recipe for poor emotional regulation skills which at a later stage translates to worse emotional outcomes [3]. Several models developed by a plethora of researchers provide pathways leading to poor parent relationship and their outcomes, these models indicate that chaotic, harsh, and neglectful parents are the root cause of the childs emotional problems. In essence this studies underscore the importance of parent relationship to the family.

Overall, the literature on the current study gives emphasis to the effects of family relationships particularly the risks posed by parentto-parent relationship on children welfare. According to the family theory perspective, each family member has a role and rules to respect and that the boundaries and interactions in the family pattern develops certain behaviours among family members. Any changes in this patterns may lead to balance or dysfuction of the system. Psychologist Dalton Perterson suggests "A family unit is like a sponge, they model each other and incorporate what they see and experience from each other into their lives". There is also evidence to suggest that family environment, pattern and parenting styles affects the developmental process of children, that is, emotionally, behavioural and socially [1].

Based on the background information this paper examines the research literature on the impact of family relationship on children academic performance, with special interest on inter-parent relations. Several researches under child development shows that parent issues among them parent socio-economic status, parent responsibilities and family relationships exert considerable effects on children academic wellbeing, behavior as well as their mental capabilities [2,4]. This review examines the scope of inter-parent relationship, describe the relationship between inter-parental relationship effects and student academic performance and finally generalize the results.

\section{Study Methodology}

This review involved a two-fold process in finding relevant literatures related to the current studies. First, studies were searched using key word searches. Several words were used in connection to inter-parent relationships such as family conflicts, divorce, marriage, child support, affection, stress and privacy. Student performance related words were also used. Extensive series of cross-searches on the study topic using Hindawi research database, which enabled the simultaneous search of multiple databases such as academia.com, SAGE, psychology and behavioural sciences collection among other databases. Further the literature search was conducted using Google Scholar and via the references identified in the articles from the given databases and sites.

Secondly, the articles were screened to verify their authenticity. The articles were evaluated in terms of their research design and methods and the type of journal that is whether peer-reviewed or not, we accepted peer-reviewed journals only (by looking at whether the journal has an abstract, restrained and thoughtful, footnotes and citations, bibliography and authors credentials among other criterions). The topic, abstract and objectives of the study were also considered to examine whether the study based on the issues to related to the current study.

The focus of these searches was to access full text documents and was not limited to a particular date range. Majority of the documents were journal articles, book chapters and research reports.

\section{Results and Discussion}

The literature consists of two parts that is the findings accumulating to inter-parent relationship variables and the findings of other studies that analyze inter-parent relationships construct in terms of a set of underlying variables. The findings are then discussed in light of the effects of inter-parent relationships on the performance of students.

\section{Emotional responses}

Emotional responses in this case refers to how parents express their emotions in relation to their thoughts, feelings or behaviour to each other and their effects to their children's school performance. Psychological experts conclusively suggest that it is usually normal for people to feel overwhelmed by stress and confused by their feelings, and therefore in a family setting this feelings must be controlled otherwise it might cause disastrous consequennces. This variable appears in many family relationship researches and yields strong positive association with student academic achievement, further the variable was assocaited with several factors such as work, drug abuse, parental duties and other stress factors [5]. For example parent emotional responses is the strongest predictor of family conflicts (overall $r=0.40$ ) in the study conducted by Adrian, as well in a study conducted by Gregory [6] which established a greater effect of parent emotional responses on family relations $(d=0.86)$ [6]. On this variable 18 papers were reviewed and generally parent emotional responses had a significant effect on student achievement. For instance Kelly argues that emotional response effects are direct and have direct impact on all parties in a family unit [7]. Parents in some cases tend to express this variable through there children. He further reports that children were fully exposed to aggresiveness and behavioural problems in families where parents had problems in containing their emotions. Wilson and Daly posits that relationships in which partners failed to understand emotional character of each other in most cases ended up destructively and that in such like marriage institutions behaviour of children was the most affected. According to the studies conducted by Cummings et al. and Maccoby parent-to-parent emotional reaction was found to be a significant predictor of children psychological difficulties especially in married, divorced and remarried families [8,9]. Children are often emotionally upset when they encounter conflicting responses among their parents, more so if the conflict is originating from the issues emanating from them and that this factors directly have effect on child study behaviour. In contrast they feel good and positively perform academically in a continued and warmth relations between the parents [4].

\section{Child support}

All children have rights to support from both parents, even when these parents do not live together anymore. This support can be financial, emotional or any other form as long as the child is satisfied not beyond his limits [10-12]. Child support variable was referred to in eleven articles. They all reported positive association with student performance.In a handbook presented by the State of Michigan on child support understanding, it is stated that its the duty of every parent to support their child and that for this to work parents need to work together. The involvement of both parents 
provides the child with chances they need to reach their potential [13]. Paul investigated the impact of family formation change on the cognitive, social and emotional wellbeing of children, he found that parent healthy relationships yielded positive cooperation betwen parents in child's emotional and financial well-being $(\mathrm{P}<0.001)$, and that separated parents who maintained good relationship inclined to the child may feel a greater commitment to providing for children's needs although they posed consequencial threats to the behaviour of the child [12]. In some studies child support appeared to be one of the strongest predictor of mothe father relationship, for instance in a study conducted by David, he reported that child support is initiated by both parents and is positioned in the role of forming and maintaining healthy family relationships $(\beta=0.27, \mathrm{P}<0.001)[14]$. In another article it was noted that, with cordinated child support among parents a child perceives that parents have good relationship and therefore creating a peace of $\operatorname{mind}(\mathrm{r}=0.39, \mathrm{P}<0.001)$. This obviously translates into positive child performance in school, however poor parent relations can block child support and can cause disastrous consequences to the child's academical, psychological and behavioural characteristcs [15-18].

\section{Individual parenting style}

The definition of this variable adopts the definition of psychologist Martin of the Wema Consultants that parenting style refers to the manner in which parents associate with each other and children. It involves communication and demonstration of values, behaviours and standards that are adopted by both parties. This perspective is also demontrated in Bowen's theory of family relationships. In this theory it is stipulated that in a family as a unit, all parties influences each others behaviour and character $[10,15]$.

There are different types of parenting styles, although this types may be put into two dimensions, that is responsive (authoritative) and unresponsive (authoritarian). Table 1 below shows a summary of parenting styles as presented by Maccoby and Martin [19]. In this case two parenting styles will be used, authoritative and authoritarian parenting style.

Authoritative: Reseaches reflecting on authoritative parentings shows a significant effect on family cooperation and democracy, this style reflects a balance between freedom and responsibility [1820]. Knafo and Plomin charges that in a family where authoritative parenting is applied, one parent must be submissive to the other, this in turn creates differentiated child attitude to both parents, although both parties may contribute to a certain issues one side either father or mother makes the final decision [21]. Chao [22] in his study on the consequences of parenting style using a 5 point likert scale found that authoritative figures in a family are the controllers of the family $(\mathrm{M}=3.97, \mathrm{SD}=0.689)$ and that they are associated with harshness and withdrawal of love $(M=4.07, S D=0.380)$. In another study authoritative parenting was significantly associated with parent disintegration $(\mathrm{r}=0.37, \mathrm{P}<0.001)$ [23]. More so, this type of parenting created emphathism and consciousness.

Authoritarian: This parenting style was characterised by parents who maintain close relationship, it may involve monitoring to the limit of seting rules and boundaries. This style focuses on order, discipline and high standards $[24,25]$. Research indicates that parent to parent

\begin{tabular}{|c|c|c|}
\hline & Demanding & Undemanding \\
\hline Response & Authoritative & Indulgent \\
\hline Unresponsive & Authoritarian & Neglectful \\
\hline
\end{tabular}

Table 1: Maccoby and Martin's Four Parenting Styles. conflicts in this type of parenting arises from the child and close supervision. For instance Steinberg, et al. showed that athoritarian parenting style generally explained child emanating conflicts $(\beta=0.11, \mathrm{P}<0.01)$ and that it fully build child behaviour and school performance $(\beta=0.12, P<0.01)[26]$. In a study conducted by Smith and Thornberry, there was a significant relationship between authoritarian parenting style and child academic performance $(\mathrm{r}=0.300, \mathrm{P}<0.01)$, this may be attributed to supervision and strict parent characters [27].

\section{Summary of the Reviewed Literature}

In summary, there is strong association between father-mother relationship and the student academic performance, in specific the associations appear to be;

i. Interparent emotional responses

ii. Interparent child support, and

iii. Individual parenting style (authoritative and authoritarian)

Even though all these variables representing father-mother relationship shows a significant relationship to the academic performance of students, they present different effects to the child, individual parents and the family as a whole [28-30]. The studies shows interactions between variables such as parent break up/unity, child mental growth and behaviour and family growth among other variables $[8,14,25]$.

\section{Conclusions}

Numerous studies reviewed in the current study shows that the quality of parent relationships has significant effects to the child's academic outcomes as well as family unity [31,32]. Correlational studies indicate modest associations between mother-father relationship and student academic performance. Consistent relationships as reviewed shows support for the individual emotional control, cooperation on child support and controlling individual parenting style.

Parent to parent relationship may have influencial capacity in the child's well-being. It is therefore an individual parent's responsibility to understand each other's behaviour and keep family rules [33-35]. This may help in the growth and development of a healthy family unit.

\section{References}

1. Adams E (2004) Beyond Quality: Parental and Residential Stability Children's Adjustment. Current Directions in Psychological Science 210-213.

2. Maccoby E (2000) Parenting and its effects on children; on reading and misreading behaviour genetics. Annual Review of Psychology.

3. Lehman B, Taylor S, Kiefe C, Seeman T (2009) Relationship of Early Life Stress and Psychological Functioning to Blood Pressure in the Cardia Study. Health Psychology.

4. Cummings E, Goeke-Morey M, Dukewich T (2002) Children's Responses to Mothers' and Father's Emotionality and Conflict Tactics during Marital Conflict in the Home. Journal of Family Psychology.

5. Andrew J, Hops H, Duncan C (1997) The Moderating Effect of the Relationship with the Parent. Journal of Family Psychology.

6. Gregory M (2008) Emotional, Cognitive and Family Systems Mediators of Children's Adjustment to Interpersonal Conflict. J Fam Psychol 22: 843-854.

7. Kelly J (1993) Current Research on Children's Post Divorce Adjustment: No simple answers Family and Conciliation Courts Review.

8. Cummings E, Goeke-Morey M, Raymond J (2004) Fathers in Family Context: Effects of Marital Quality and Marital Conflict. In: Lamb ME (ed.) The Role of the Father in Child Development. Wiley: Hoboken. 
Citation: Maina AR, Kitainge K (2018) A Review of the Effects of Mother-Father Relationship on Academic Performance of Students. Arts Social Sci J 9: 339. doi: 10.4172/2151-6200.1000339

Page 4 of 4

9. Maccoby E (1998) The Two Sexes: Growing Up Apart, Coming Together Cambridge, MA: Harvard University Press.

10. CRCW (2003) Barriers to Marriage Among Fragile Families. Princeton Princeton University.

11. Stephanie V (2001) Births to Teenagers in the United States: National Vital Statistical Reports.

12. Paul A (2005) The Impact of Family Formation Change on the Cognitive, Social and Emotional Wellbeing of the Next Generation: The Future of Children.

13. Michigan SO (2008) Understanding Child Support: A Handbook for Parents. Department of Human Services, Michigan, USA

14. David C (2000) Balancing the Needs of Families and Employers: The Family and Medical Leave Surveys. Washington.

15. Nadine F, James D, Choi H (2002) Transitions to Caregiving, Gender, and Psychological Well-Being. Journal of Marriage and Family.

16. Robert B (2002) Child Adjustment in Joint-Custondy Versus Sole Custody Arrangement: A meta analytic Review. Journal of Family Psychology 16: 91102.

17. Kordi A, Baharudin R (2010) Parenting Attitude and Style and Its Effect on Children's School Achievements. International Journal of Psychological Studies 2.

18. Fletcher A, Steinberg L, Sellers E (1999) Adolescents' Well-being as a Function of Perceivd inter-Parent Inconsistency. Journal of Marriage and the Family.

19. Maccoby E, Martin J (1983) Socialization in the Context of the Family: ParentChild Interaction. New York: Wiley.

20. Kamins M, Dweck C (2000) Person versus Process Praise and Criticism: Implications for Contigent Self-Worth and Coping. Developmental Psychology.

21. Knafo A, Plomin R (2008) Prosocial Behaviour from Early to Middle Childhood: Genetic and Environmental Influences on Stability and Change. Developmental Psychology

22. Chao R (2001) Extending Research on the Consequences of Parenting Style for Chinese Americans and European Americans. Child Development 72.
23. Turkel Y (2008) Parenting Styls and Learned Resourcefulness of Turkish Adolescents. Adolescence.

24. Danesh H (1998) The Authoritarian Family and Its Adolescents. Can Psychiatric Association Journal.

25. Azmitia M, Cooper C (2001) Good or Bad? Peer Influences on Latino and European American Adolescents' Pathways through School. Journal of Education for Students Placed at Risk 6: 45-71.

26. Steinberg, L, Mounts N, Dornbusch S (1991) Authoritative Parenting and Adolescent across varied Ecological Niches. Journal of Research on Adolescence.

27. Smith C, Thornberry T (1995) The Relationship between Childhood Maltreatment and Adolescent Involvement in Delinquency. Criminology.

28. Adrian BK, John WT, Martin O, George CP, Jason PC (2011) Family Relationship Quality and Early Alcohol Use: Evidence for Gender Specific Risk Process. Journal of Studies on Alcohol and Drugs.

29. Anderson S, Howerd A (2012) Building Father Mother Relationships. Nothern Carribean University.

30. Brooks L (2007) Jacket' doesn't fit; Paternity test requests up, fathers suspicious Jamaica Gleaner.

31. Harvey J, Delfabbro P (2004) Psycholocial Resilience in Disadvantaged Youth A Critical Overview. Austrualian Psychologist.

32. Krevans J, Gibbs J (1996) Parent's Use of Inductive Discipline: Relations to Children's Empathy and Prosocial Behaviour. Child Development.

33. Pearlin L, Schooler C (1978) The Structure of Coping. Journal of Health and Social Behaviour 19: 2-21.

34. Shute VJ, Eric GH, Jody SU, Rim R (2011) A Review of the Relationship betwen Parental Involvement and Secondary School Students' Academic Achievement. Education Research International.

35. Specht J, Polgar J, King G (2003) How we got hear. Resilience: Learning from People with Disabilities and the Turning Points in Their Lives. Praeger: Westpot, CT. 